\section{№ 47}

\section{Diest}

Diretoria de Estudos e Políticas do Estado, das Instituições e da Democracia

Janeiro de 2021

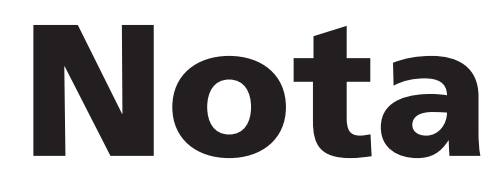

Técnica

MOBILIZAÇÃO DA ACADEMIA EM INSTÂNCIAS COLEGIADAS DURANTE CRISE DA COVID-19: MAPEAMENTO DAS EXPERIÊNCIAS NOS ESTADOS BRASILEIROS

\author{
Pedro Lucas de Moura Palotti \\ Natália Massaco Koga \\ Bruno Gontyjo do Couto
}

Maricilene Isaira Baia do Nascimento 



\section{Nota}

Técnica

MOBILIZAÇÃO DA ACADEMIA EM INSTÂNCIAS COLEGIADAS DURANTE CRISE DA COVID-19: MAPEAMENTO DAS EXPERIÊNCIAS NOS ESTADOS BRASILEIROS

\section{№ 47}

Diest

Diretoria de Estudos e Políticas do Estado, das Instituições e da Democracia
Pedro Lucas de Moura Palotti Natália Massaco Koga Bruno Gontyjo do Couto Maricilene Isaira Baia do Nascimento 


\section{Governo Federal}

Ministério da Economia

Ministro Paulo Guedes

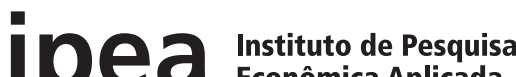 \\ ipea}

Fundação pública vinculada ao Ministério da Economia, o Ipea fornece suporte técnico e institucional às ações governamentais - possibilitando a formulação de inúmeras políticas públicas e programas de desenvolvimento brasileiros - e disponibiliza, para a sociedade, pesquisas e estudos realizados por seus técnicos.

\section{Presidente}

Carlos von Doellinger

Diretor de Desenvolvimento Institucional Manoel Rodrigues Junior

Diretora de Estudos e Políticas do Estado

das Instituições e da Democracia

Flávia de Holanda Schmidt

\section{Diretor de Estudos e Políticas}

\section{Macroeconômicas}

José Ronaldo de Castro Souza Júnior

Diretor de Estudos e Políticas Regionais,

Urbanas e Ambientais

Nilo Luiz Saccaro Júnior

Diretor de Estudos e Políticas Setoriais de Inovação e Infraestrutura

André Tortato Rauen

Diretora de Estudos e Políticas Sociais

Lenita Maria Turchi

Diretor de Estudos e Relações Econômicas

e Políticas Internacionais

Ivan Tiago Machado Oliveira

Assessor-chefe de Imprensa

e Comunicação (substituto)

João Cláudio Garcia Rodrigues Lima

Ouvidoria: http://www.ipea.gov.br/ouvidoria

URL: http://www.ipea.gov.br 


\section{Nota}

Técnica

MOBILIZAÇÃO DA ACADEMIA EM INSTÂNCIAS COLEGIADAS DURANTE CRISE DA COVID-19: MAPEAMENTO DAS EXPERIÊNCIAS NOS ESTADOS BRASILEIROS

\section{№ 47}

\section{Diest}

Diretoria de Estudos e Políticas do Estado, das Instituições e da Democracia

Janeiro de 2021
Pedro Lucas de Moura Palotti Natália Massaco Koga Bruno Gontyjo do Couto Maricilene Isaira Baia do Nascimento 


\section{EQUIPE TÉCNICA}

\section{Pedro Lucas de Moura Palotti}

Especialista em políticas públicas e gestão governamental em exercício no Ipea.

\section{Natália Massaco Koga}

Especialista em políticas públicas e gestão governamental em exercício no Ipea.

\section{Bruno Gontyjo do Couto}

Pesquisador do Subprograma de Pesquisa para o Desenvolvimento Nacional (PNPD) na Diretoria de Estudos e Políticas do Estado, das Instituições e da Democracia (Diest) do Ipea.

\section{Maricilene Isaira Baia do Nascimento}

Pesquisadora do PNPD na Diest//pea.

DOI: http://dx.doi.org/10.38116/ntdiest47

As publicações do Ipea estão disponíveis para download gratuito nos formatos PDF (todas) e EPUB (livros e periódicos). Acesse: <http://www.ipea.gov.br/ portal/publicacoes $>$.

As opiniões emitidas nesta publicação são de exclusiva e inteira responsabilidade dos autores, não exprimindo, necessariamente, o ponto de vista do Instituto de Pesquisa Econômica Aplicada ou do Ministério da Economia.

É permitida a reprodução deste texto e dos dados nele contidos, desde que citada a fonte. Reproduções para fins comerciais são proibidas. 


\section{SUMÁRIO}

1 INTRODUÇÃO . .7

2 COMUNIDADES CIENTÍFICAS, BUROCRACIA ESTATAL E INFORMAÇÃO CIENTÍFICA NA PRODUÇÃO DE POLÍTICAS PÚBLICAS NO CONTEXTO DE PANDEMIA DA COVID-19 .8

3 ESTRATÉGIA METODOLÓGICA 9

4 RESULTADOS 10

5 CONSIDERAÇÕES FINAIS... 15

REFERÊNCIAS 17 



\section{INTRODUÇÃO}

A crise sanitária da Covid-19 desencadeou um conjunto de reações emergenciais em todo mundo. O rápido espalhamento da doença em nível global pode ser evidenciado pelo curto prazo entre a primeira notificação oficial da Organização Mundial de Saúde (OMS) sobre o surgimento de uma misteriosa pneumonia em Wuhan, na China, em 31 de dezembro de 2019, e a declaração oficial da mesma organização de que estava em curso uma pandemia, em 11 de março de 2020.

Essa rápida evolução impôs a adoção de respostas rápidas em diversos campos de atuação governamental. Conforme descreveram Hale et al. (2020), em iniciativa de pesquisa de escala mundial promovida pela Blavatnik School of Goverment, da Universidade de Oxford, foram identificadas medidas sanitárias (investimentos de emergência em saúde e em vacinas), de isolamento e distanciamento social (fechamento de escolas, locais de trabalho, do transporte público, restrições de movimento interno de pessoas, cancelamento de eventos públicos e controle de viagens internacionais), econômicas (medidas fiscais e monetárias) e de comunicação governamental (campanhas de informação pública).

Nesse sentido, diversos especialistas, particularmente na área de epidemiologia e infectologia, tornaram-se atores centrais para auxiliar governos durante o processo decisório de adoção de medidas de mitigação e enfretamento da crise. Em muitos casos, houve a constituição de instâncias formais de consulta a especialistas, no formato de conselhos e comitês dedicados ao assessoramento de dirigentes governamentais. A criação dessas instâncias e sua utilização durante o processo decisório tem sido enfatizada no discurso político, o que remete para os diversos papeis que a mobilização de evidências científicas pode assumir no policy making (Amara, Ouimet e Landry, 2004; Parkhurst, 2017).

No caso brasileiro, um elemento adicional a ser considerado é a multiplicidade de governos decorrente do federalismo. O federalismo brasileiro conferiu a estados e municípios autonomia política para implementar um conjunto de ações governamentais em diversos campos de políticas públicas, muito embora a formulação tenha se mantido centralizada em nível federal, que acumula extenso rol de temáticas cuja normatização é competência privativa da União (Arretche, 2013; Soares e Machado, 2018).

No âmbito da crise sanitária em curso, em 23 de março de 2020, o Partido Democrático Trabalhista (PDT) ajuizou a Ação Direta de Inconstitucionalidade (ADI) no 6.341 no Supremo Tribunal Federal (STF), questionando dispositivos da Medida Provisória 926/2020. No dia seguinte, o ministro Marco Aurélio proferiu liminar ressaltando a competência concorrente de estados, municípios e do Distrito Federal em questões relacionadas à saúde pública, conforme disposto no art. 23, inciso II, da Constituição Federal. Em 15 de abril de 2020, por maioria, o plenário do STF referendou esse entendimento.

Assim, cabe ao governo federal legislar em âmbito nacional, resguardada a autonomia de governadores e prefeitos para legislar em seus territórios específicos. Desse modo, não cabe ao Presidente da República, por exemplo, a definição por decreto de serviços e atividades essenciais que seja obrigatória para todos os entes federados. Foi reiterada, portanto, a autonomia política dos entes subnacionais para estabelecer medidas necessárias ao enfretamento da crise, às quais correspondem, no caso desses governos, principalmente às medidas de distanciamento e isolamento nacional. Esse cenário acentua a necessidade de exploração, no caso brasileiro, de como as decisões têm sido tomadas em âmbito subnacional e qual o papel concebido aos especialistas e às eventuais instâncias criadas para interlocução entre academia e gestão no enfrentamento da crise.

Esta Nota Técnica tem como objetivo geral responder à seguinte pergunta de pesquisa: onde, a partir de quando e por que meios institucionais tem se dado a participação de especialistas para assessoramento científico dos gestores estaduais no enfrentamento da Covid-19?

Os objetivos específicos dessa proposta são os seguintes:

- investigar como instâncias formais de assessoramento têm se constituído e se há um assento formal para especialistas;

- propor um indicador de classificação das instâncias de assessoramento em âmbito subnacional (ex. natureza da interação, nível de recursos, composição); e

- investigar os efeitos da coordenação regional sobre as capacidades analíticas dos governos estaduais, tomando como referência o Consórcio do Nordeste.

A próxima seção discutirá como comunidades científicas podem ser mobilizadas pela burocracia estatal para contribuir com o processo decisório. A seguir, na terceira seção, será traçada a estratégia metodológica utilizada. A quarta seção apresentará os resultados observados para que, nas conclusões, sejam sintetizados os achados obtidos e a agenda futura de pesquisa. 


\section{COMUNIDADES CIENTÍFICAS, BUROCRACIA ESTATAL E INFORMAÇÃO CIENTÍFICA NA PRODUÇÃO DE POLÍTICAS PÚBLICAS NO CONTEXTO DE PANDEMIA DA COVID-19}

O conjunto de ideias e princípios reunidos sob a denominação de Políticas Públicas baseadas em Evidências (PPBE) surge, no final da década de 1990, no Reino Unido, defendendo o uso na tomada de decisões de evidências produzidas a partir de pesquisas sistemáticas e robustas sobre o que funciona nas políticas públicas (Davies et al., 2000). Embora a PPBE venha ganhando adeptos nos governos ao longo dos anos, estudos empíricos recentes, conduzidos em diversos países, têm demonstrado que há pouco uso (ao menos de forma explícita e direta) pelos burocratas de pesquisas científicas no processo de produção de políticas públicas (Vésely et al., 2018; Newman et al., 2016).

A chamada "teoria das duas comunidades" levanta desafios para o estabelecimento de uma dinâmica de uso de pesquisas pelo Estado e de interações entre a comunidade científica e a comunidade da gestão das políticas (Caplan, 1979). Em um primeiro momento, a premissa defendida foi a de que esses campos desfrutam de uma separação muito nítida, com baixa, ou quase nenhuma, interação, principalmente em razão de as duas comunidades possuírem valores, incentivos e linguagens distintos entre si e pela resistência ou desinteresse do Estado no uso desse tipo de evidência (Caplan, 1979; Newman et al., 2016).

No entanto, os autores nesse debate vêm refletindo que o uso de evidências científicas trabalha em uma lógica diferente no campo da burocracia estatal. Bogenschneider et al. (2013) chamam a atenção para o quão crucial é melhor entender a cultura profissional e institucional em que operam os pesquisadores e a burocracia: "[p]esquisadores e policymakers ocupam papéis únicos e operam em culturas profissionais e institucionais distintas" (Bogenschneider et al., 2013, p. 264). Essas diferentes culturas socializam também de modo distinto o pensar, o agir e o perceber o mundo.

Cherney, Head e Povey (2015) apontam que a cultura organizacional (preferências e constrangimentos) sob a qual os atores desse campo podem estar inseridos e a infraestrutura da informação com a qual trabalham podem dizer muito sobre o quanto a pesquisa científica se entrelaça nas agências governamentais, de qual é o seu fluxo e a sua influência. Não somente a cultura, mas também a infraestrutura organizacional e a habilidade individual dos usuários podem possibilitar diferentes engajamentos com diferentes tipos de evidências, entre elas as científicas (Newman et al., 2017).

Sobre a intensidade e continuidade de uso de evidências pela burocracia estatal, Newman et al. (2016) ainda sugerem que, em vez de operar dentro de duas comunidades, a relação entre pesquisadores e policymakers mais provavelmente ocorre em um longo espectro de interação, "com alguns funcionários públicos se envolvendo mais de perto com a pesquisa acadêmica do que outros” (Newman et al., 2016, p. 25). Além disso, Weiss (1977) já incluía no debate a reflexão de que o "maior uso de pesquisa social não é a aplicação de dados específicos a decisões específicas. Em vez disso, tomadores de decisão tendem a usar pesquisas indiretamente, como fonte de ideias, informação, e orientações ao mundo" (Weiss, 1977, p. 531, tradução nossa). Nessa corrente mais crítica, Head (2015) propõe que pratictioners fazem uso direto de pesquisas acadêmicas somente em circunstâncias excepcionais, ou seja, o uso instrumental para a tomada de decisão é muito pontual. Newman et al. (2016), sugerem, inclusive, que seria mais apropriado falarem evidence-informed policy (políticas públicas informadas por evidências) do que evidence-based policy (políticas públicas baseadas em evidências).

Refletindo o contexto da Covid-19, Weible et al. (2020) concluem que a crise e as grandes incertezas possibilitaram a centralidade de experts e cientistas nos governos: "[a] pandemia Covid-19 elevou repentinamente esta comunidade às esferas pública e política mundial” (Weible et al., 2020, p. 8, tradução nossa). ${ }^{1}$ Nesse cenário, os diferentes usos do vocabulário científico para diferentes propósitos resultam em "um aumento simultâneo da confiança em relação a especialistas científicos e técnicos e da politização da informação científica e técnica” (idem, ibidem). Além disso, os autores destacam que essa demanda pontual por basear as decisões em informações científicas desafiou ambas as comunidades: experts - a habilidade para simplificar e comunicar a informação técnica; policymakers - a habilidade em balancear o julgamento político e responsabilidade no uso de informação técnica e científica.

Contudo, como apontam Nutley et al. (2007), os trabalhos dedicados a propor medidas para aproximação das duas comunidades refletem, em geral, sobre como os atores, tanto especialistas como policymakers, podem aprimorar suas habilidades e sua atuação. Em que pese a relevância dessa abordagem focada no nível dos indivíduos, há poucos trabalhos que buscam identificar e analisar medidas voltadas ao estabelecimento de novas relações entre o campo da pesquisa e gestão da política de modo mais abrangente e formal.

1. Ao mesmo tempo, observou-se a existência de tensões quanto à utilização das recomendações científicas. Isso aponta para a natureza política da decisão de adotar evidence-informed policy, particularmente onde a lideranças políticas adotaram posturas negacionistas ou de minimização 
Uma frente de pesquisa nesse sentido seria aquela que chama a atenção para a "governança das evidências", a qual entende que a aproximação das duas comunidades pode ser facilitada por meio do comprometimento e criação de procedimentos e mecanismos formais para uma melhor gestão das evidências na produção das políticas. Parte desses estudos sustenta, ainda, que mecanismos estruturados de governança das evidências podem garantir maior atenção aos princípios democráticos na tomada de decisão, uma vez que permitiriam deliberação e dariam maior transparência a tais processos. Desta forma, tornariam explícito que a decisão, embora possa se valer de diferentes fontes de evidência, recai ao fim e ao cabo sobre os representantes eleitos e responsabilizáveis pelas decisões (Parkhurst, 2016). Nesse sentido, tais instâncias de governança poderiam contribuir para a avaliação e tradução de evidências produzidas por diversas fontes (French, 2019).

Não obstante as perspectivas positivas levantadas por esta abordagem, há que se considerar os desafios que ela carrega tanto em relação às demandas de tempo e esforço dos atores e organizações para a criação e manutenção de tais mecanismos de governança, quanto a eventuais efeitos negativos que eles podem produzir, como o excesso de protocolos e auditorias para a garantia de conformidade. Esse tipo de iniciativa torna necessárias inovações nas práticas acadêmicas e na forma em que as políticas são produzidas (French, 2019).

Cabe lembrar, por fim, que Newman et al. (2016) argumentam que a metáfora de "comunidades distintas e separadas" provavelmente não é uma maneira apropriada de entender a maneira como academia e policy se relacionam porque os atores envolvidos nessa relação não são homogêneos e nem isolados. Aliás, Oliver e Faul (2018) sugerem que o uso de evidência, na prática, é um processo complexo e um resultado também complexo, sendo, portanto, essencialmente um processo relacional.

No contexto brasileiro, ainda há poucos casos de iniciativas formais estabelecidas com o intuito de aproximar a gestão e a academia para apoiar a condução das políticas públicas. As instâncias formais recentemente criadas pelos governos estaduais para o enfrentamento à Covid-19 podem ser consideradas inovações nesse sentido e serão examinadas nesta nota técnica, considerando a discussão acima apresentada.

Na seção seguinte, apresentaremos a estratégia metodológica adotada para compreender como as instâncias formais de gestão e/ou assessoramento têm sido constituídas pelos gestores estaduais e qual o papel dos especialistas nessas instâncias.

\section{ESTRATÉGIA METODOLÓGICA}

A pesquisa foi desenvolvida a partir da análise documental relacionada ao enfrentamento da pandemia da Covid-19 pelos governos subnacionais. Foram pesquisados de maneira sistemática os sites dos governos estaduais, bem como os principais normativos editados por esses entes governamentais. A pesquisa seguiu as referências de levantamento de dados em curso produzido pelo Ipea (Moraes, 2020a; 2020b), tendo construído uma base de dados das instâncias formais de assessoramento nos níveis regional e estadual brasileiros ${ }^{2}$ que poderão ser utilizadas em análises e pesquisas futuras.

A partir da análise documental empreendida, foram traçadas quatro variáveis com o intuito de diferenciar os formatos distintos de instâncias formais de gestão e/ou assessoramento (comitê, comissão, gabinete etc.): i) existência ou não dessas instâncias; ii) participação de especialistas ou instituições acadêmicas de ensino e pesquisa; iii) menção explícita à concepção de PPBE; e iv) organização de um comitê técnico-científico específico para lidar com a crise da Covid-19.

A seguir, essas variáveis e suas respectivas categorias são esmiuçadas.

\subsection{Variável 1 - existência de uma instância formal de gestão e/ou assessoramento (comitê, comissão, gabinete etc.) voltada ao enfrentamento da pandemia Covid-19: a instância precisa ter sido instituída por portaria, decreto ou lei}

- Sim (1) - o estado possui uma instância formal criada por meio de legislação específica.

- Não (0) - o estado não possui uma instância formal criada por meio de legislação específica. 
3.2 Variável 2 - a instância formal de gestão e/ou assessoramento conta com a participação oficial de especialistas da área e instituições acadêmicas e de pesquisa ${ }^{3}$

- Total (2) - a instância formal conta com participação oficial tanto de especialistas quanto de instituições acadêmicas e de pesquisa.

- Parcial (1) - a instância formal conta com participação oficial de especialistas da área, mas não conta com instituições acadêmicas e de pesquisa.

- Inexistente (0) - a instância formal não conta com participação oficial de especialistas e de instituições acadêmicas e de pesquisa.

3.3 Variável 3 - o marco legal que regulamenta a instância contém em seus princípios e diretrizes quaisquer atributos que remetam a Políticas Públicas Baseadas em Evidências ${ }^{4}$

- Sim (1) - o marco legal apresenta princípio ou diretriz correspondente à abordagem da PPBE.

- Não (0) - o marco legal não apresenta nenhum princípio ou diretriz correspondente à abordagem da PPBE.

3.4 Variável 4 - existência de um comitê técnico-científico específico, composto majoritariamente por especialistas da área e/ou instituições acadêmicas e de pesquisa, voltado ao enfrentamento da pandemia Covid-19

- Total (2) - o estado conta com um comitê técnico-científico específico, com função de deliberação sobre as medidas de enfrentamento à pandemia.

- Parcial (1) - o estado conta com um comitê técnico-científico específico, com função consultiva no enfrentamento à pandemia.

- Inexistente (0) - o estado não conta com um comitê técnico-científico específico.

Como forma de sintetizar a classificação das experiências estaduais de organização de instâncias colegiadas, propomos o Índice de Proximidade Gestão-Academia (IPGA), formado pelo somatório de cada uma das dimensões observadas: ${ }^{5}$

$\mathrm{IPGA}=\mathrm{V} 1+\mathrm{V} 2+\mathrm{V} 3+\mathrm{V} 4$

A partir dessa estratégia metodológica, a próxima seção irá apresentar os resultados obtidos de maneira comparativa e depois focada em algumas experiências particulares.

\section{RESULTADOS}

\subsection{Análise comparativa dos estados}

A tabela 1 aponta para a comparação entre os 26 estados e o Distrito Federal quanto à criação e formato institucional de comitês, comissões ou gabinetes de gestão e/ou assessoramento para a pandemia da Covid-19. A primeira observação que pode ser realizada é a de que todos os estados criaram algum tipo de instância dessa natureza. Desse conjunto, no entanto, dezenove estados (70\% do total) criaram instâncias formais que contam com a participação de especialistas da área e/ou instituições acadêmicas e de pesquisa, dos quais dezesseis (60\% do total) contam com a participação tanto de especialistas da área quanto de instituições acadêmicas e de pesquisa simultaneamente.

Dentre os 26 estados e o Distrito Federal, somente em oito casos (30\% do total) houve a organização de instâncias colegiadas cujos princípios ou diretrizes, no âmbito do marco legal de criação, corresponderiam às ideias e princípios da PPBE.

3. A distinção adotada remete à origem da indicação para participação das instâncias científicas. É possível que um cientista ou especialista seja nomeado diretamente pelo chefe do executivo, não representando diretamente uma organização. É possível também que uma universidade participe indicando diretamente um representante que, embora não seja um especialista, representa essa instituição. Assim, o indicador diferencia essas duas possibilidades de composição das instâncias científicas.

4. A identificação de atributos de PPBE se deu através da leitura e interpretação dos documentos legais. Em alguns casos a referência é explícita, como do Rio Grande do Sul, que postula como competência do seu comitê "Reunir e interpretar evidências científicas... que possam auxiliar nas decisões do Governo do Estado" (Rio Grande do Sul, 2020). Em outros casos, a referência não é explícita, mas clara, como Tocantins que atribui ao seu comitê a função de "compartilhar resultados de estudos e oferecer soluções a partir de uma abordagem científica" (Tocantins, 2020).

5. As variáveis 2 e 4 possuem uma escala maior ( 0 a 2), impactando de forma mais significativa o IPGA. Essa escolha se deu em razão da importância dessas dimensões do ponto de vista teórico - composição e poder decisório, respectivamente - e da variabilidade observada nos casos empíricos levantados. 
Por fim, somente onze estados (40\% do total) instituíram comitês específicos de caráter eminentemente técnico-científico para o enfrentamento da pandemia Covid-19, dos quais sete deles possuem função estritamente consultiva e quatro contam com funções deliberativas.

Desse modo, Amapá e Distrito Federal apresentam o escore mais elevado no IPGA (= 6) porque possuem comitês técnico-científicos específicos com participação de especialistas da área e instituições acadêmicas e de pesquisa, com funções consultivas e deliberativas no enfrentamento à pandemia. Além de apresentarem atributos correspondentes às ideias e princípios da PPBE em suas diretrizes legais.

Em relação aos estados que obtiveram escore 5 no IPGA, podemos observar dois grupos distintos. O primeiro, formado por Pará e Pernambuco, é caracterizado por possuir instâncias técnico-científicas com composição de especialistas e instituições acadêmicas e função deliberativa, mas não apresenta atributos da PPBE em suas diretrizes legais. O segundo grupo, representado por Rio de Janeiro, Rio Grande do Sul, São Paulo e Tocantins, possui comitês técnico-científicos específicos com participação de especialistas e instituições acadêmicas, apresentando atributos da PPBE em suas diretrizes, mas que detêm apenas funções consultivas no enfrentamento à pandemia.

Na parte inferior da tabela, Acre, Espírito Santo, Minas Gerais, Paraíba, Piauí, Paraná, Santa Catarina e Sergipe apresentaram o escore mais baixo no IPGA (1). Esses estados criaram instâncias formais de gestão e/ou assessoramento para o enfrentamento da pandemia, mas não contam com a participação de especialistas ou instituições acadêmicas, não apresentam atributos da PPBE no seu marco legal e não constituíram comitês técnico-científicos próprios. ${ }^{6}$

TABELA 1

Pontuação de cada variável considerada na avaliação dos estados (31 ago. 2020)

\begin{tabular}{|c|c|c|c|c|c|}
\hline UF & $\begin{array}{c}\text { V1 } \\
\text { Instância formal para } \\
\text { enfrentamento da } \\
\text { pandemia }\end{array}$ & $\begin{array}{c}\text { V2 } \\
\text { Instância conta com } \\
\text { participação de espe- } \\
\text { cialistas }\end{array}$ & $\begin{array}{c}\text { V3 } \\
\text { Marco legal adere à } \\
\text { PPBE }\end{array}$ & $\begin{array}{c}\text { V4 } \\
\text { Comitê científico } \\
\text { próprio }\end{array}$ & $\begin{array}{c}\text { Índice de } \\
\text { Proximidade } \\
\text { Gestão-Academia } \\
\text { (IPGA) } \\
(0-6)\end{array}$ \\
\hline AP & 1 & 2 & 1 & 2 & 6 \\
\hline $\mathrm{DF}$ & 1 & 2 & 1 & 2 & 6 \\
\hline $\mathrm{PA}$ & 1 & 2 & 0 & 2 & 5 \\
\hline $\mathrm{PE}$ & 1 & 2 & 0 & 2 & 5 \\
\hline $\mathrm{RJ}$ & 1 & 2 & 1 & 1 & 5 \\
\hline $\mathrm{RS}$ & 1 & 2 & 1 & 1 & 5 \\
\hline SP & 1 & 2 & 1 & 1 & 5 \\
\hline TO & 1 & 2 & 1 & 1 & 5 \\
\hline MA & 1 & 1 & 1 & 1 & 4 \\
\hline $\mathrm{RN}$ & 1 & 2 & 0 & 1 & 4 \\
\hline $\mathrm{RO}$ & 1 & 2 & 0 & 1 & 4 \\
\hline $\mathrm{AL}$ & 1 & 2 & 0 & 0 & 3 \\
\hline $\mathrm{AM}$ & 1 & 2 & 0 & 0 & 3 \\
\hline $\mathrm{CE}$ & 1 & 2 & 0 & 0 & 3 \\
\hline GO & 1 & 2 & 0 & 0 & 3 \\
\hline MS & 1 & 2 & 0 & 0 & 3 \\
\hline $\mathrm{MT}$ & 1 & 2 & 0 & 0 & 3 \\
\hline BA & 1 & 1 & 1 & 0 & 3 \\
\hline $\mathrm{RR}$ & 1 & 1 & 0 & 0 & 2 \\
\hline $\mathrm{AC}$ & 1 & 0 & 0 & 0 & 1 \\
\hline ES & 1 & 0 & 0 & 0 & 1 \\
\hline
\end{tabular}

6. Entretanto, é importante ressaltar que Paraíba, Piauí e Sergipe integram o Comitê Científico criado pelos nove estados do Consórcio Nordeste no dia 31 de março de 2020. Como será discutido no tópico 4.3, a inclusão desse Comitê na contagem do índice desloca os estados da região para a parte superior da tabela. 


\begin{tabular}{|c|c|c|c|c|c|}
\hline UF & $\begin{array}{c}\text { V1 } \\
\text { Instância formal para } \\
\text { enfrentamento da } \\
\text { pandemia }\end{array}$ & $\begin{array}{c}\text { V2 } \\
\text { Instância conta com } \\
\text { participação de espe- } \\
\text { cialistas }\end{array}$ & $\begin{array}{c}\text { V3 } \\
\text { Marco legal adere à } \\
\text { PPBE }\end{array}$ & $\begin{array}{c}\text { V4 } \\
\text { Comitê científico } \\
\text { próprio }\end{array}$ & $\begin{array}{c}\text { Índice de } \\
\text { Proximidade } \\
\text { Gestão-Academia } \\
\text { (IPGA) } \\
(0-6)\end{array}$ \\
\hline MG & 1 & 0 & 0 & 0 & 1 \\
\hline $\mathrm{PB}$ & 1 & 0 & 0 & 0 & 1 \\
\hline PI & 1 & 0 & 0 & 0 & 1 \\
\hline $\mathrm{PR}$ & 1 & 0 & 0 & 0 & 1 \\
\hline SC & 1 & 0 & 0 & 0 & 1 \\
\hline SE & 1 & 0 & 0 & 0 & 1 \\
\hline
\end{tabular}

Fontes: AP (Amapá, 2020a; 2020b); DF (Distrito Federal, 2020a; 2020b); PA (Pará, 2020); PE (Pernambuco, 2020a; 2020b); RJ (Rio de Janeiro, 2020a; 2020b); RS (Rio Grande do Sul, 2020); SP (São Paulo, 2020a; 2020b); TO (Tocantins, 2020a; 2020b); MA (Maranhão, 2020a; 2020b); RN (Rio Grande do Norte, 2020a; 2020b); RO (Rondônia, 2020a; 2020b); AL (Alagoas, 2020); AM (Amazonas, 2020); CE (Ceará, 2020); GO (Goiás, 2020); MS (Mato Grosso do Sul, 2020); MT (Mato Grosso, 2020a; 2020b); BA (Bahia, 2020a; 2020b); RR (Roraima, 2020;); AC (Acre, 2020); ES (Espírito Santo, 2020); MG (Minas Gerais, 2020); PB (Paraíba, 2020); PI (Piauí, 2020); PR (Paraná, 2020); SC (Santa Catarina, 2020); SE (Sergipe, 2020).

\subsection{Linha do tempo}

Os gráficos 1 e 2 apresentam a linha do tempo da criação de instâncias de apoio à gestão e assessoramento durante a pandemia da Covid-19, o primeiro apontando a criação de comitês mais amplos e o segundo enfocando os técnico-científicos.

Com relação aos comitês de forma mais geral, observa-se, como dissemos anteriormente, que todos os estados criaram instâncias colegiadas para lidar com a crise sanitária. Os estados do Pará e Amazonas foram os primeiros estados a criarem comitês institucionais voltados ao enfrentamento à Covid-19 no país. O Pará criou o "Comitê Técnico Assessor de Informações Estratégicas", no dia 28 de janeiro, e o Amazonas criou o "Comitê Interinstitucional Ampliado de Gestão de Emergência", no dia 29 de janeiro. Os dois comitês contam com participação de institutos de pesquisa em medicina tropical (Instituto Evandro Chagas, no Pará, e a Fundação de Medicina Tropical Doutor Heitor Vieira Dourado, no Amazonas).

Das 27 Unidades da Federação (UFs), 23 (85\%) criaram seus respectivos comitês institucionais de enfrentamento à pandemia em um curto intervalo de tempo, entre os dias 12 e 25 de março de 2020, logo após a declaração de pandemia global por parte da OMS no dia 11 de março. O primeiro caso confirmado no Brasil ocorreu no dia 26 de fevereiro.

O gráfico 2 enfoca somente os casos de estados que tenham criado comitês técnico-científicos para lidar com a crise sanitária. Como observado anteriormente, apenas dez estados e o Distrito Federal criaram instâncias colegiadas dessa natureza. O Pará se destaca mais uma vez, pois o comitê institucional criado no dia 28 de janeiro tem caráter eminentemente técnico-científico, com participação das universidades locais - Universidade Federal do Pará (UFPA), Universidade Estadual do Pará (UEPA) e Universidade Federal Rural da Amazônia (UFRA) - e do Instituto de Pesquisa em Medicina Tropical do Instituto Evandro Chagas (IEC).

A criação dos demais comitês técnico-científicos em nove estados e no Distrito Federal reproduz de certa forma a tendência dos comitês de gestão, ou seja, foram criados após a declaração de pandemia pela OMS no dia 11 de março. Contudo, é possível notar uma dispersão maior no tempo, demonstrando que a maioria foi criada algumas semanas após os comitês de gestão, ao longo, principalmente, dos meses de março e abril.

Não há uma correlação evidente entre os estados mais bem posicionados no IPGA e a premência com que foram criadas instâncias de técnico-científicas. Apesar de o Pará se destacar tanto no IPGA como na rapidez de criação dessas instâncias, Amazonas e Goiás foram céleres na criação de alguma instância de enfrentamento, porém não alcançaram as primeiras posições no IPGA, principalmente pela ausência de uma instância técnico-científica dedicada a lidar com a pandemia. 
GRÁFICO 1

Linha do tempo com a data de criação das instâncias de enfrentamento à Covid-19 nas UFs (31 ago. 2020) ${ }^{7}$

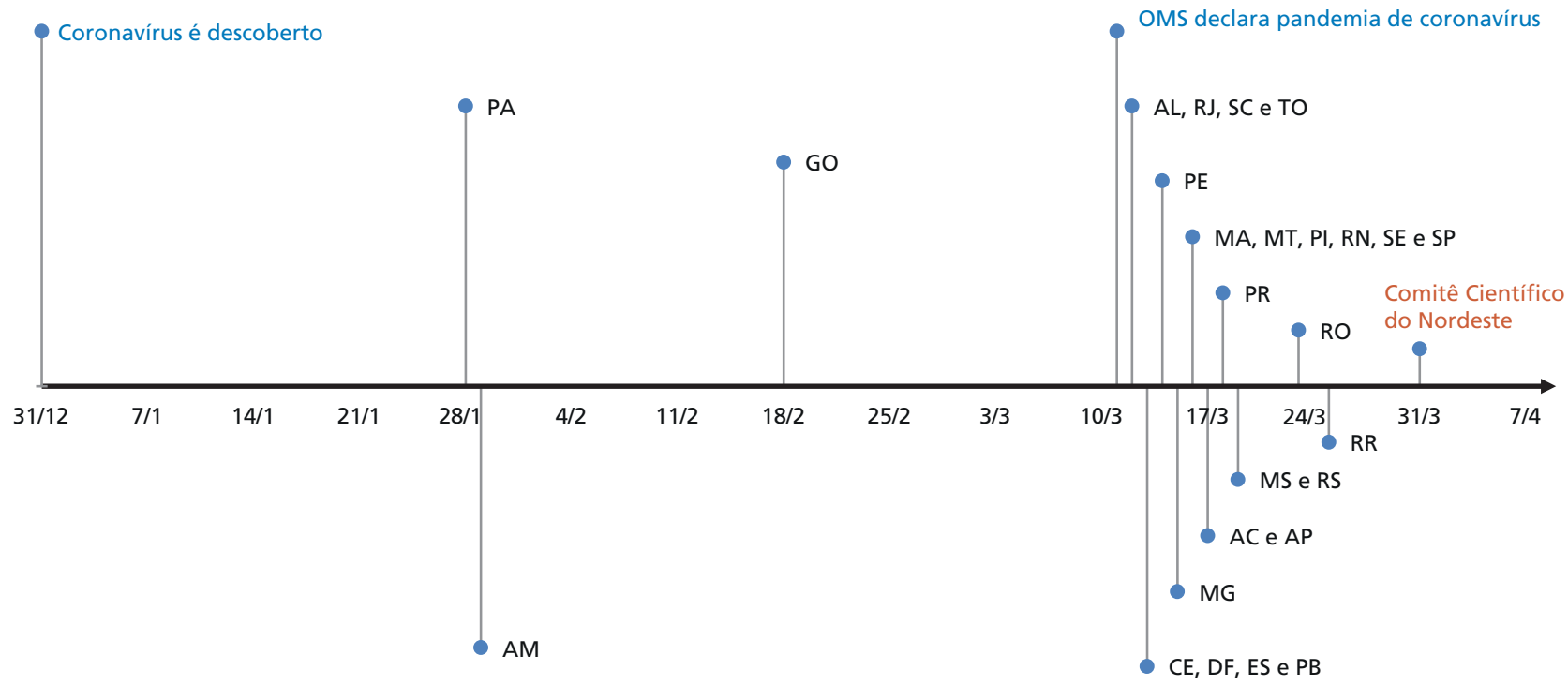

Elaboração dos autores.

GRÁFICO 2

Linha do tempo com a data de criação dos comitês científicos de enfrentamento à Covid-19 nas UFs (31 ago. 2020)

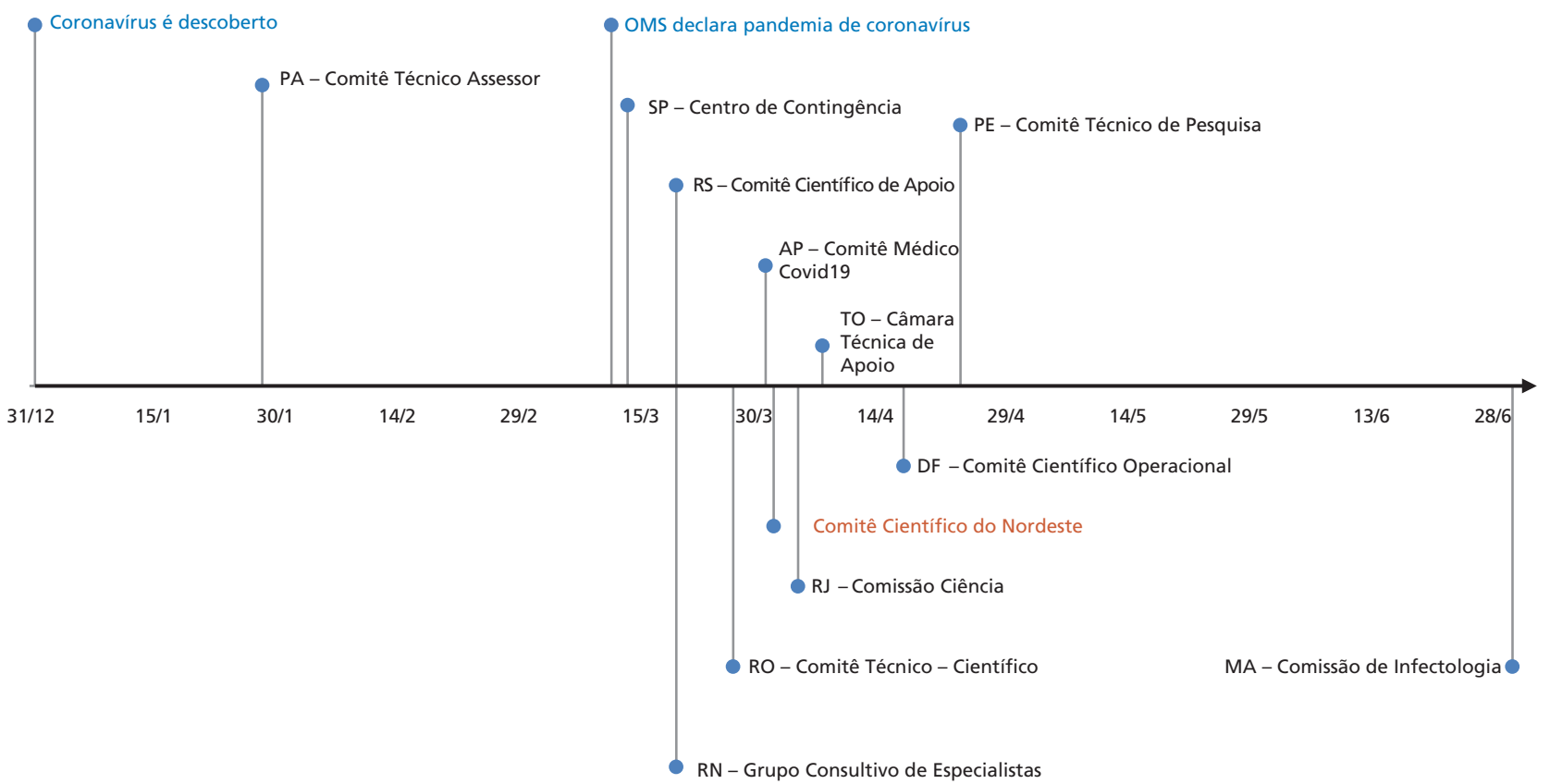

Elaboração dos autores.

\subsection{Análise qualitativa}

Apesar da tendência dos governos locais em trazer a comunidade científica para o assessoramento no combate à pandemia, diferentes configurações podem ser constatadas quanto à centralidade e relevância da comunidade científica nesse papel. Destacamos alguns casos que exemplificam essa diversidade.

7. O estado da Bahia não aparece no gráfico 1 porque não criou uma instância formal de gestão voltada para o enfrentamento da pandemia no período designado. O estado lançou mão da estrutura de vigilância já existente na Secretária Estadual de Saúde (Bahia, 2020a). O estado pontuou no índice porque, além dessa estrutura, instituiu no dia 29 de maio de 2020, o "Grupo de Trabalho Retomada Econômica" (Bahia, 2020b). Ainda vale pontuar que a Bahia liderou o Consórcio Nordeste na criação do Comitê Científico do Nordeste (GRUPO..., 2020). 


\subsubsection{O Comitê Científico do Nordeste}

O Comitê Científico do Nordeste (CCNE) é um caso representativo da centralidade concedida, do ponto de vista normativo, aos atores que produzem evidência científica. Instituído pela Resolução no 5 , de 31 de março de 2020, o Comitê Científico é formado exclusivamente por até vinte membros da comunidade científica, com representação de cada estado consorciado, para assessorá-los na tomada de decisão no enfrentamento ao novo coronavírus - "um corpo técnico com funcionamento regular fora dos quadros dos estados”, conforme caracterizam Fernandez e Pinto (2020, p. 14). Os autores também destacam a ampliação desse Comitê, "com a criação de nove subcomitês e com a articulação de dezenas de instituições e centenas de pessoas não só no Nordeste, mas em todo o Brasil e no mundo”.

Outras estratégias foram criadas com o intuito de instrumentalizar a interação e o fluxo de informações entre academia, gestão e sociedade, tais como a ferramenta de monitoramento de casos Monitora-Covid-19, boletins científicos de recomendações de medidas produzidas pelo comitê e o Projeto Mandacaru (Peres e Santana, 2020).

Para fins de exemplificação, o Projeto Mandacaru trata de uma plataforma colaborativa em que experts trazem referências de pesquisas para o debate em subcomitês temáticos e produção de documentos como síntese de evidências para disseminação junto à sociedade. De acordo com o sítio eletrônico do Projeto, ${ }^{8}$

as discussões devem ser com embasamento científico com as devidas citações das referências. Desta forma, os documentos produzidos poderão auxiliar os subcomitês nas diversas áreas e informar corretamente a população. Nosso compromisso é levar à população informações claras, objetivas, e cientificamente embasadas.

O CCNE representa, portanto, uma inovação institucional no combate à pandemia. É uma instância de assessoramento com caráter eminentemente técnico-científico, composta por especialistas e instituições acadêmicas e de pesquisa. Apresenta atributos às ideias e princípios da PPBE em seu marco legal e detém função consultiva. Assim, ao considerarmos o comitê na pontuação do índice, os nove estados nordestinos aparecem na parte superior da tabela com um escore de 5 (Pernambuco chega ao escore máximo de 6).

TABELA 2

Pontuação de cada variável considerada na avaliação dos estados, levando em conta o Comitê Científico do Nordeste (31 ago. 2020)

\begin{tabular}{|c|c|c|c|c|c|}
\hline UF & $\begin{array}{c}\text { V1 } \\
\text { Instância formal para } \\
\text { enfrentamento da } \\
\text { pandemia }\end{array}$ & $\begin{array}{l}\text { V2 } \\
\text { Instância conta com } \\
\text { participação de espe- } \\
\text { cialistas }\end{array}$ & $\begin{array}{c}\text { V3 } \\
\text { Marco legal adere à } \\
\text { PPBE }\end{array}$ & $\begin{array}{c}\mathrm{V} 4 \\
\text { Comitê científico } \\
\text { próprio }\end{array}$ & $\begin{array}{c}\text { Somatória V1-V4 } \\
(0-6)\end{array}$ \\
\hline $\mathrm{AP}$ & 1 & 2 & 1 & 2 & 6 \\
\hline $\mathrm{DF}$ & 1 & 2 & 1 & 2 & 6 \\
\hline $\mathrm{PE}$ & 1 & 2 & 1 & 2 & 6 \\
\hline $\mathrm{PA}$ & 1 & 2 & 0 & 2 & 5 \\
\hline RJ & 1 & 2 & 1 & 1 & 5 \\
\hline RS & 1 & 2 & 1 & 1 & 5 \\
\hline SP & 1 & 2 & 1 & 1 & 5 \\
\hline TO & 1 & 2 & 1 & 1 & 5 \\
\hline MA & 1 & 2 & 1 & 1 & 5 \\
\hline $\mathrm{RN}$ & 1 & 2 & 1 & 1 & 5 \\
\hline $\mathrm{AL}$ & 1 & 2 & 1 & 1 & 5 \\
\hline $\mathrm{CE}$ & 1 & 2 & 1 & 1 & 5 \\
\hline BA & 1 & 2 & 1 & 1 & 5 \\
\hline $\mathrm{PB}$ & 1 & 2 & 1 & 1 & 5 \\
\hline PI & 1 & 2 & 1 & 1 & 5 \\
\hline SE & 1 & 2 & 1 & 1 & 5 \\
\hline RO & 1 & 2 & 0 & 1 & 4 \\
\hline
\end{tabular}




\begin{tabular}{|c|c|c|c|c|c|}
\hline UF & $\begin{array}{c}\text { V1 } \\
\text { Instância formal para } \\
\text { enfrentamento da } \\
\text { pandemia }\end{array}$ & $\begin{array}{c}\text { V2 } \\
\text { Instância conta com } \\
\text { participação de espe- } \\
\text { cialistas }\end{array}$ & $\begin{array}{c}\text { V3 } \\
\text { Marco legal adere à } \\
\text { PPBE }\end{array}$ & $\begin{array}{l}\text { V4 } \\
\text { Comitê científico } \\
\text { próprio }\end{array}$ & $\begin{array}{c}\text { Somatória V1-V4 } \\
(0-6)\end{array}$ \\
\hline $\mathrm{AM}$ & 1 & 2 & 0 & 0 & 3 \\
\hline $\mathrm{GO}$ & 1 & 2 & 0 & 0 & 3 \\
\hline MS & 1 & 2 & 0 & 0 & 3 \\
\hline MT & 1 & 2 & 0 & 0 & 3 \\
\hline $\mathrm{RR}$ & 1 & 1 & 0 & 0 & 2 \\
\hline $\mathrm{AC}$ & 1 & 0 & 0 & 0 & 1 \\
\hline ES & 1 & 0 & 0 & 0 & 1 \\
\hline MG & 1 & 0 & 0 & 0 & 1 \\
\hline PR & 1 & 0 & 0 & 0 & 1 \\
\hline SC & 1 & 0 & 0 & 0 & 1 \\
\hline
\end{tabular}

Fonte: Consórcio Nordeste (2020).

Elaboração dos autores.

\subsubsection{Distrito Federal}

O caso do Distrito Federal já traz uma configuração mista de atores para participar no assessoramento do combate à pandemia, e indica menos centralidade aos atores da comunidade científica, quando comparado ao caso do Consórcio Nordeste, apesar de haver uma portaria específica dedicada à instituição de um comitê científico.

O Decreto no 40.512, de 13 de março de 2020, instituiu o "Grupo Executivo para o desenvolvimento de ações de prevenção e mitigação à Covid-19 e à Dengue”, composto por representantes de órgãos e entidades governamentais. E a Portaria no 241, de 16 de abril de 2020, instituiu o "Comitê Científico Operacional de Estratégias de Enfrentamento à Covid-19” que, além de representantes indicados por instituições científicas locais - Universidade de Brasília (UnB) e Fundação Oswaldo Cruz (Fiocruz) -, também é composto pelos atores do Instituto de Gestão Estratégica do Distrito Federal (IGES/DF). Como ambas instâncias contam com representantes da comunidade científica e há previsão de funções deliberativas na instância científica (Comitê Científico), o caso do Distrito Federal somou 2 pontos nas variáveis V2 e V4, atingindo a pontuação mais elevada no IPGA.

\subsubsection{Rio Grande do Sul}

O Estado do Rio Grande do Sul é o caso de maior diversidade de representação na constituição de diferentes instâncias voltadas ao assessoramento no combate à pandemia, criadas sob a mesma legislação. O Decreto no 55.129 , de 19 de março de 2020, instituiu um Gabinete de Crise, um Conselho de Crise e um Grupo Interinstitucional de combate ao novo coronavírus. Um exemplo de criação institucional que centraliza a relação entre burocracia estatal, comunidade econômica e representativa de classe e comunidade científica. O Conselho de Crise, em particular, abriga a participação de representantes indicados pelas principais instituições científico-universitárias do estado, razão pela qual o caso do Rio Grande do Sul adicionou 2 pontos à variável V2 no IPGA. Contudo, como o Comitê Científico, criado pelo mesmo decreto, não prevê funções deliberativas, apenas consultivas, a variável V4 manteve-se em 1 ponto, resultando em um IPGA de 5 pontos.

\section{CONSIDERAÇÕES FINAIS}

A pandemia da Covid-19 desafia a área de pesquisa sobre evidências nas políticas públicas a buscar a compreensão das oportunidades, dificuldades, dinâmicas e processos na relação entre dois campos que operam em lógicas muito distintas, mas que foram centrais no contexto em questão: burocracia estatal e campos de produção de conhecimento científico. Essa conjuntura crítica não somente tornou premente essa relação, mas também contextualizou o debate do técnico e do político, ou ainda, o debate do racional e do pragmático.

Outro aspecto também importante é compreender como diferentes atores, em diferentes lugares, estruturam a relação dessas dimensões, que, em geral, pode ser dividida como "aqueles que produzem conhecimento e/ou informações de suporte" e "aqueles que tomam decisões a partir de conhecimento e informação", uma divisão, por óbvio, mais pragmática que normativa. Outro ponto de relevância também é chamar a atenção para o fato de que não apenas a burocracia 
e os governantes tiveram de adaptar seus discursos e práticas políticas, os produtores de conhecimento científico também experimentaram gerar evidências em contexto de crise política, social e econômica, muitas vezes lidando com deslegitimação e precarização estrutural, o que complexifica muito mais a compreensão da relação desses dois campos distintos.

A seguir, serão destacados os cinco principais resultados deste estudo.

1) Todos os estados criaram comitês de assessoramento com o intuito de apoiar a tomada de decisão face à complexidade da pandemia e à necessidade de respostas rápidas. Esse processo ocorreu em curtíssimo espaço de tempo e já no início, ou mesmo antes, da declaração de estado de pandemia pela OMS.

2) Menos da metade dos estados constituiu comitês técnico-científicos específicos e a criação dessas instâncias de encontro formal entre a academia e a gestão ocorreu mais lentamente do que no caso dos comitês de assessoramento.

3) Há casos como o Comitê Científico do Nordeste que demonstram desdobramentos no sentido de buscar estabelecer relações mais abrangentes e perenes entre academia e gestão.

4) Não foi identificada uma coordenação central formal no processo de criação dessas instâncias, o que pode ter gerado uma maior heterogeneidade no tipo de envolvimento previsto para a academia nos diversos casos.

5) A experiência prévia do Consórcio do Nordeste, que permitiu constituir rapidamente o Comitê Científico do Nordeste com adesão de todos os estados da região, demonstra potencialidades da coordenação horizontal quanto à otimização e qualificação dos subsídios trazidos pela academia, assim como para a definição de medidas voltadas ao enfrentamento de problemas públicos comuns. Essa potencialidade reflete-se na pontuação de todos os estados nordestinos no IPGA.

Em suma, os dados apresentados revelam esforços e intencionalidades nos governos estaduais no sentido da criação de instâncias de interlocução com a comunidade científica. Essas experiências revelam potencialidades na promoção de avanços tanto na governança de evidências (governance of evidence), como na avaliação de evidências (knowledge assessment) para que a produção científica possa, em alguma medida, informar decisões governamentais em contexto de grande complexidade e desconhecimento sobre o problema público em questão (enfrentamento à Covid-19) e seus efeitos nos diversos campos sociais.

Vale destacar que este estudo não permite identificar em que medida as recomendações das instâncias examinadas foram efetivamente seguidas pelos governos, uma vez que se limitou a analisar os dados normativos que caracterizaram a formalização de seus desenhos, como tipos de representação, finalidade e natureza. Pesquisas futuras nesse sentido seriam importantes à medida que essas experiências ganhem mais maturidade. Estudos que examinem eventuais processos de difusão dessas experiências pelos estados brasileiros também podem permitir a compreensão de questões como a motivação da adoção pelos diferentes governos desses arranjos entre governo e academia, o que é de fato transferido dessas experiências, os indutores e inibidores dessas transferências, entre outros aspectos.

De todo modo, os resultados deste estudo sugerem três principais recomendações:

- Compreender que a governança da relação entre academia e gestão é um tema próprio e não pode ser negligenciado. Como a literatura no campo já aponta, o trajeto entre a produção da academia e a gestão das políticas é algo a ser pavimentado. Criar arranjos institucionais perenes e efetivos, como as propostas dos comitês científicos examinados neste estudo, podem intensificar e qualificar a interação entre academia e gestão e ter efeitos para a aproximação das duas comunidades. Do lado da gestão, tem a potencialidade de fortalecer a médio e longo prazo a capacidade analítica dos entes governamentais na definição de medidas e políticas públicas e, do lado da academia, de aprimorar os seus processos de produção de conhecimento de modo a considerar a realidade da gestão e se tornar mais visível e relevante para esse contexto.

- Diretrizes federais traçadas a partir do aprendizado de boas práticas como essas já iniciadas pelos governos locais podem diminuir heterogeneidades e fortalecer as interlocuções entre gestão-academia para o enfrentamento de problemas públicos comuns.

- Ações voltadas à coordenação, seja vertical como horizontal, devem ser consideradas como formas de otimizar e melhor direcionar tanto os recursos despendidos pelos vários entes para a criação desse tipo de arranjo de governança entre gestão e academia, como as medidas a serem adotadas a partir das recomendações geradas por esses arranjos.

Por fim, a utilidade, a interpretação, a relevância e os significados da evidência científica dependem das relações sociais em curso. No entanto, "[e]xistem lacunas significativas em nossa compreensão de como os relacionamentos influenciam o uso de evidências" (Oliver e Faul, 2018, p. 2). Ainda sobre esse ponto, sob o aspecto metodológico, Trostle et al. (1999) já criticavam que pouco se busca compreender sobre o que os próprios pesquisadores e policymakers dizem a 
respeito da relação entre eles e sobre o contexto pontual no qual essa relação está sendo estabelecida. Nesse sentido, os espaços formais de assessoramento dos gestores por especialistas tornam-se lócus privilegiado de análise não apenas das potencialidades, mas também dos limites e resultados do estabelecimento e fortalecimento desses laços sociais para o modo de produzir políticas públicas, uma agenda de pesquisa futura para a qual este trabalho aponta.

\section{REFERÊNCIAS}

ACRE. Portaria no 33, de 17 de março de 2020. Dispõe sobre o Comitê de Acompanhamento Especial do Covid-19. Diário Oficial, Rio Branco, 2020. Disponível em: <https://bit.ly/2M2Z7bP>.

ALAGOAS. Decreto no 69.463, de 12 de março de 2020. Dispõe sobre a criação efuncionamento do Gabinete de Criseda Situação de Emergência - GCSE para combate ao coronavírus Covid-19 no estado de Alagoas. Diário Oficial, Maceió, 2020. Disponível em: <https://bit.ly/3sArzm0>.

AMAPÁ. Decreto no 1.488 , de 28 de março de 2020. Institui o Comitê Médico de enfrentamento ao Covid-19, vinculado ao Centro de Operações de Emergências em Saúde Pública - COESP, e adota outras providências. Diário Oficial, Macapá, 2020a. Disponível em: <https://bit.ly/3ing0Kp>.

Decreto no 1.376, de 17 de março de 2020. Institui no âmbito do Estado do Amapá o Centro de Operações de Emergências em Saúde Pública (COESP) em virtude do risco de epidemia causado pelo Coronavírus (Covid-19), para o fim que especifica e dá outras providências. Diário Oficial, Macapá, 2020b. Disponível em: <https://bit.ly/2NiB2yf>.

AMARA, N.; OUIMET, M.; LANDRY, R. New Evidence on Instrumental, Conceptual, and Symbolic Utilization of University Research in Government Agencies. Science Communication, v. 26, n. 1, p. 75-106, 2004.

AMAZONAS. Portaria nº 010/2020/DIPRE/FVS-AM. Constitui o Comitê Interinstitucional de Gestão de Emergências em Saúde Pública para Resposta Rápida aos Vírus Respiratórios, com ênfase no novo coronavírus (2019-nCoV). Diário Oficial, Manaus, 2020. Disponível em: <https://bit.ly/3bTDtl0>.

ARRETCHE, M. Quando instituições federativas fortalecem o governo central? In: HOCHMAN, G.; FARIA, C. A. P. (Orgs.). Federalismo e Políticas Públicas no Brasil. Rio de Janeiro: Editora Fiocruz, 2013. p. 65-90.

BAHIA. Centro de Operações de Emergência em Saúde (Coes). Portal do Governo Estadual. Salvador, 2020a. Disponível em: <https://bit.ly/3ingf8h>.

Decreto no 19.732, de 29 de maio de 2020. Institui o Grupo de Trabalho para Estudos de Retomada Econômica Pós-Pandemia e dá outras providências. Diário Oficial, Salvador, 2020b. Disponível em: <https://bit.ly/38TuFcY>.

BOGENSCHNEIDER, K.; LITTLE, O.; JOHNSON, K. Policymakers' use of social science research: looking within and across policy actors. Journal of Marriage and Family, v. 75, n. 2, p. 263-275, 2013.

CEARÁ. Decreto no 33.509, de 13 de março de 2020. Institui o Comitê Estadual de Enfrentamento à Pandemia do Coronavírus, e dá outras providências. Diário Oficial, Fortaleza, 2020. Disponível em: <https://bit.ly/3qJDFaX>.

CHERNEY, A.; HEAD, B.; POVEY, J. Use of academic social research by public officials: exploring preferences and constraints that impact on research use. Evidence \& Policy A Journal of Research Debate and Practice, v. 11, p. 169-188, 2015.

CONSÓRCIO NORDESTE - CONSÓRCIO INTERESTADUAL DE DESENVOLVIMENTO SUSTENTÁVEL DO NORDESTE. Resolução no 5, de 2020. Institui o Comitê Científico de combate à pandemia do novo coronavírus no âmbito do Consórcio Interestadual de Desenvolvimento Sustentável do Nordeste - Consórcio Nordeste. Diário Oficial, Salvador, 2020 .

DISTRITO FEDERAL. Decreto no 40.512, de 13 de março de 2020. Cria o Grupo Executivo para o desenvolvimento de ações de prevenção e mitigação ao Covid-19 e à Dengue, adota medidas de contenção e enfretamento de ambas as enfermidades no âmbito do Distrito Federal e dá outras providências. Diário Oficial do Distrito Federal, Brasília, 2020a. Disponível em: <https://bit.ly/2LZYVdd>.

Portaria no 241 , de 16 de abril de 2020. Cria o Comitê Científico Operacional de Estratégias de Enfrentamento à Covid-19 e dá outras providências. Diário Oficial do Distrito Federal, Brasília, 2020b. Disponível em: <https://bit. ly/3nWyTok>.

ESPÍRITO SANTO. Decreto no 4593, de 13 de março de 2020. Decreta o estado de emergência em saúde pública no Estado do Espírito Santo e estabelece medidas sanitárias e administrativas para prevenção, controle e contenção de riscos, danos e agravos decorrentes do surto de coronavírus (Covid-19) e dá outras providências. Diário Oficial, Vitória, 2020. Disponível em: <https://bit.ly/3oWalof $>$. 
FERNANDEZ, M.; PINTO, H. A. Estratégia intergovernamental de atuação dos estados brasileiros: o Consórcio Nordeste e as políticas de saúde no enfrentamento à Covid-19. Revista Saúde em Redes, v. 6, n. 2, p. 7-21, 2020.

FRENCH, R. D. Is it time to give up on evidence-based policy? Four answers. Policy \& Politics, v. 47, n. 1, p. 151-168, 2019.

GOIÁS. Portaria no 416/2020SES. Institui, no âmbito da Secretaria de Estado da Saúde de Goiás, o Centro de Operações de Emergência em Saúde Pública para o novo Coronavírus (COE-nCoV). Diário Oficial, Goiânia, 2020. Disponível em: <https://bit.ly/3p9iChD>.

GRUPO formado por governadores do Nordeste cria comitê científico para combate ao coronavírus. G1 BA, 31 mar. 2020. Disponível em: <https://glo.bo/3nUZoL7>.

MARANHÃO. Portaria no 413, de 30 de junho de 2020. Cria a Comissão de Infectologia para o combate e prevenção ao COVID-19 no âmbito da Secretaria de Saúde do Estado do Maranhão. Diário Oficial, São Luís, 2020a. Disponível em: <https://bit.ly/2XTXO1A>.

Decreto nº 35660, de 16 de março de 2020. Dispõe sobre os procedimentos e regras para fins de prevenção da transmissão da Covid-19, institui o Comitê Estadual de Prevenção e Combate à Covid-19 e dá outras providências.

Diário Oficial, São Luís, 2020b. Disponível em: <https://bit.ly/2NbrxRf>.

MATO GROSSO. Decreto no 537, de 29 de junho de 2020. Institui o Grupo de Trabalho Central - GTC para desenvolver ações de monitoramento e articulação de estratégias com o fim de reduzir os impactos da transmissão da Covid-19 em territórios indígenas. Diário Oficial, Cuiabá, 2020a. Disponível em: <https://bit.ly/3oVMFZL>.

Decreto nº 407, de 16 de março de 2020. Dispõe sobre as medidas para enfrentamento da emergência de saúde pública de importância internacional decorrente do coronavírus (2019-nCoV) a serem adotados pelo Poder Executivo do Estado de Mato Grosso, e dá outras providências. Diário Oficial, Cuiabá, 2020b. Disponível em: <https://bit. ly/3inyydt $>$.

MATO GROSSO DO SUL. Resolução nº 11/SES/MS, de 19 de março de 2020. Institui o Centro de Operações de Emergência referente ao novo coronavírus, de caráter emergencial, para auxiliar na definição de diretrizes estaduais para vigilância, prevenção e controle, bem como o acompanhamento e avaliação das ações desenvolvidas pela Secretaria de Estado de Saúde (SES) e Instituições Envolvidas. Diário Oficial, Campo Grande, 2020. Disponível em: <https://bit. ly/3qxvONn>.

MINAS GERAIS. Decreto no 47.886, de 15 de março de 2020. Dispõe sobre medidas de prevenção ao contágio e de enfrentamento e contingenciamento, no âmbito do Poder Executivo, da epidemia de doença infecciosa viral respiratória causada pelo agente Coronavírus (Covid-19), institui o Comitê Gestor do Plano de Prevenção e Contingeciamento em Saúde do Covid-19 - Comitê Extraordinário Covid-19 e dá outras providências. Diário Oficial, Belo Horizonte, 2020. Disponível em: <https://bit.ly/3quesB2>.

MORAES, R. F. Medidas legais de incentivo ao distanciamento social: comparação das políticas de governos estaduais e prefeituras das capitais no Brasil. Brasília: Ipea, 2020a. (Nota Técnica, n. 16). Disponível em: <https://bit.ly/3oYhIEe>.

Covid-19 e medidas legais de distanciamento social: isolamento social, gravidade da pandemia e análise do período de 25 de maio a 7 de junho de 2020. Brasília: Ipea, 2020b. (Nota Técnica, n. 22). Disponível em: <https://bit. ly/3quk6TI>.

NEWMAN, J.; CHERNEY, A.; HEAD, B. W. Do policy makers use academic research? Reexamining the "two communities" theory of research utilization. Public Administration Review, v. 76, n. 1, p. 24-32, 2015.

Policy capacity and evidence-based policy in the public service. Public Management Review, v. 19, n. 2, p. 157-174, 2017.

NUTLEY, S. M.; WALTER, I.; DAVIES, H. T. O. Using evidence: how research can inform public services. Bristol: Policy Press, 2007.

OLIVER, K.; FAUL, M. V. Networks and network analysis in evidence, policy and practice. Evidence \& Policy: A Journal of Research, Debate and Practice, v. 14, n. 3, p. 369-379, 2018.

PARÁ. Portaria no 077, de 28 de janeiro de 2020. Institui o Comitê Técnico Assessor de Informações Estratégicas e Respostas Rápidas à Emergência em Vigilância em Saúde referentes ao Novo Coronavírus (NCOV). Diário Oficial, Belém, 2020. Disponível em: <https://bit.ly/3qJEmRB>.

PARAÍBA. Decreto no 40.122, de 13 de março de 2020. Declara situação de Emergência no Estado da Paraíba ante ao contexto de decretação de Emergência em Saúde Pública de Interesse Nacional pelo Ministério da Saúde e a declaração da condição de pandemia de infecção humana pelo Coronavírus definida pela Organização Mundial de Saúde. Diário Oficial, João Pessoa, 2020. Disponível em: <https://bit.ly/2Krb3n7>. 
PARANÁ. Decreto no 4.259, de 18 de março. Institui o Comitê de Gestão de Crise para o Covid-19 no estado do Paraná. Diário Oficial, Curitiba, 2020. Disponível em: <https://bit.ly/39MAGY2>.

PARKHURST, J. The politics of evidence: from evidence-based policy to the good governance of evidence. London: Routledge, 2017.

PEREZ, O. C.; SANTANA, L. Ações do Consórcio Nordeste no combate à pandemia de Covid-19. Revista NAU Social, v. 11, n. 21 , p. 259-70, 2020.

PERNAMBUCO. Decreto no 48.809, de 14 de março de 2020. Regulamenta, no estado de Pernambuco, medidas temporárias para enfrentamento da emergência de saúde pública de importância internacional decorrente do coronavírus, conforme previsto na Lei Federal no 13.979, de 6 de fevereiro de 2020. Diário Oficial, Recife, 2020a. Disponível em: $<$ https://bit.ly/38STaXS>.

Decreto no 48.970, de 23 de abril de 2020. Institui o Comitê Técnico de Pesquisa, Desenvolvimento e Inovação para o enfrentamento da emergência de saúde pública decorrente do novo coronavírus. Diário Oficial, Recife, $2020 \mathrm{~b}$. Disponível em: <https://bit.ly/38WEHtU>.

PIAUÍ. Decreto no 18.884, de 16. de março de 2020. Regulamenta a Lei no 13.979, de 6 de fevereiro de 2020, para dispor no âmbito do estado do Piauí, sobre as medidas de emergência de saúde pública de importância internacional e tendo em vista a classificação da situação mundial do novo coronavírus como pandemia, institui o Comitê de Gestão de Crise, e dá outras providências. Diário Oficial, Teresina, 2020. Disponível em: <https://bit.ly/3im42AE>.

RIO DE JANEIRO. Decreto no 47.061, de 5 de maio de 2020. Dispõe sobre a criação de comissão especial denominada Comissão Ciência RJ no Combate à Covid-19 (COMCIÊNCIARJCOVID). Diário Oficial, Rio de Janeiro, 2020a. Disponível em: <https://bit.ly/3bP6pe3>.

Decreto no 46.969, de 12 de março de 2020. Dispõe sobre a criação do Gabinete de Crise para Enfrentamento da Emergência de Saúde Pública de Importância Internacional decorrente do Coronavírus, e dá outras providências. Diário Oficial, Rio de Janeiro, 2020b. Disponível em: <https://bit.ly/39HgTtk>.

RIO GRANDE DO NORTE. Portaria nº 759, de 19 de março de 2020. Institui o Grupo Consultivo de Especialistas no âmbito do Comitê de Enfrentamento as Emergências em Saúde Pública de Importância Estadual do Rio Grande do Norte. Diário Oficial, Natal, 2020a. Disponível em: <https://bit.ly/3qrrz5O>.

Decreto no 29.521, de 16 de março de 2020. Institui o Comitê Governamental de Gestão da Emergência em Saúde Pública decorrente do Coronavírus (Covid-19). Diário Oficial, Natal, 2020b. Disponível em: <https://bit. ly/3nTeGQp>.

RIO GRANDE DO SUL. Decreto no 55.129, de 19 de março de 2020. Institui Gabinete de Crise para o Enfrentamento da Epidemia Covid-19, Conselho de Crise para o Enfrentamento da Epidemia Covid-19, Grupo Interinstitucional de Monitoramento das Ações de Prevenção e Mitigação dos efeitos do Covid-19 no Sistema Prisional do Estado do Rio Grande do Sul e Centro de Operação de Emergência - Covid 19 (COE Covid-19) do Estado do Rio Grande do Sul. Diário Oficial, Porto Alegre, 2020. Disponível em: <https://bit.ly/3c3ph9p >.

RONDÔNIA. Decreto no 24.893, de 23 de março de 2020. Institui o Comitê Interinstitucional de Prevenção, Verificação e Monitoramento dos Impactos da Covid-19. Diário Oficial, Porto Velho, 2020a. Disponível em: <https://bit. ly/39GNnUo>.

RONDÔNIA. Comitê Técnico-Científico inicia colaboração com hospitais e unidades básicas de saúde de Rondônia. Portal Oficial do Governo Estadual, Porto Velho, 2020b. Disponível em: <https://bit.ly/38WseGF>.

RORAIMA. Decreto nº 28.657, de 25 de março de 2020. Dispõe sobre a criação do Comitê de Crise para Enfrentamento da Emergência de Saúde Pública de Importância Internacional e Nacional decorrente do Coronavírus (Covid-19) no âmbito do Estado de Roraima, e dá outras providências. Diário Oficial, Boa Vista, 2020. Disponível em: <https://bit. ly/3qv1GCj>.

SANTA CATARINA. Portaria nํㅜ 179, de 12 de março de 2020. Institui o Centro de Operações de Emergência em Saúde (COES), destinado a integrar as ações e serviços de saúde. Diário Oficial, Florianópolis, 2020. Disponível em: <https:// bit.ly/39HhbjU>.

SÃO PAULO. Decreto nº 64.864, de 16 de março de 2020. Dispõe sobre a adoção de medidas adicionais, de caráter temporário e emergencial, de prevenção de contágio pelo Covid-19 (Novo Coronavírus), e dá providências correlatas. Diário Oficial, São Paulo, 2020a. Disponível em: <https://bit.ly/3qv1LWD>.

Resolução SS no 27, de 13 de março de 2020. Dispõe sobre o Centro de Operações do Coronavírus e dá providencias correlatas. Diário Oficial, São Paulo, 2020b. Disponível em: <https://bit.ly/3sDPBg7>. 
SERGIPE. Decreto ํㅜ 40560, de 16 de março de 2020. Dispõe sobre a decretação de situação de emergência na saúde pública do estado de Sergipe, em razão da disseminação do vírus Covid-19 (novo coronavírus) e regulamenta as medidas para enfrentamento da crise de saúde pública de importância internacional, nos termos da Lei (Federal) nº 13.979, de 6 de fevereiro de 2020. Diário Oficial, Aracaju, 2020. Disponível em: <https://bit.ly/3oWbyVl>.

SOARES, M. M.; MACHADO, J. A. Federalismo e Políticas Púbicas. 1. ed. Brasília: Enap, 2018. v. 10. 112 p.

TOCANTINS. Decreto no 6.064, de 12 de março de 2020. Instala o Comitê de Crise para a Prevenção, Monitoramento e Controle do Vírus Covid-19 - novo Coronavírus. Diário Oficial, Palmas, 2020a. Disponível em: <https://bit. ly/3bWLG8h>.

Decreto no 6.080, de 6 de abril de 2020. Dispõe sobre a formação de Câmara Técnica de Apoio ao Comitê de Crise para a Prevenção, Monitoramento e Controle do Vírus Covid-19 - novo Coronavírus, e adota outras providências. Diário Oficial, Palmas, 2020b. Disponível em: <https://bit.ly/3bR2n4P>.

TROSTLE, J.; BRONFMAN, M.; LANGER, A. How do researchers influence decision-makers? Case studies of Mexican Policies. Health Policy and Planning, v. 149, n. 2, p. 103-114, 1999.

VESELÝ, A.; OCHRANA, F.; NEKOLA, M. When evidence is not taken for granted: the use and perception of "evidence" in the Czech Republic Ministries. NISPAcee Journal of Public Administration and Policy, v. 11, n. 2, p. 219-234, 2018.

WEIBLE, C. M. et al. Covid-19 and the policy sciences: initial reactions and perspectives. Policy Sci, v. 53, p. 225-241, 2020.

WEISS, C. H. Research for policy's sake: the enlightenment function of social research. Policy Analysis, v. 4, n. 3, p. 531-45, 1997. 

Ipea - Instituto de Pesquisa Econômica Aplicada

\section{EDITORIAL}

\section{Chefe do Editorial}

Reginaldo da Silva Domingos

\section{Assistentes da Chefia}

Rafael Augusto Ferreira Cardoso

Samuel Elias de Souza

\section{Supervisão}

Camilla de Miranda Mariath Gomes

Everson da Silva Moura

\section{Editoração}

Aeromilson Trajano de Mesquita

Cristiano Ferreira de Araújo

Danilo Leite de Macedo Tavares

Herllyson da Silva Souza

Jeovah Herculano Szervinsk Junior

Leonardo Hideki Higa

\section{Capa}

Danielle de Oliveira Ayres

Flaviane Dias de Sant'ana

The manuscripts in languages other than Portuguese published herein have not been proofread.

\section{Livraria Ipea}

SBS - Quadra 1 - Bloco J - Ed. BNDES, Térreo

70076-900 - Brasília - DF

Tel.: (61) 2026-5336

Correio eletrônico: livraria@ipea.gov.br 

Composto em linux libertine 10/13 (texto) 



\section{Missão do Ipea}

Aprimorar as políticas públicas essenciais ao desenvolvimento brasileiro por meio da produção e disseminação de conhecimentos e da assessoria ao Estado nas suas decisões estratégicas.

\section{ipea Econômica Aplicada}

